\title{
PERBANDINGAN HASIL BELAJAR SISWA DENGAN MENGGUNAKAN MEDIA AUDIOVISUAL DAN TANPA MEDIA AUDIOVISUAL PADA MATERI STRUKTUR DAN FUNGSI SEL SEBAGAI UNIT TERKECIL KEHIDUPAN DI KELAS XI SMA SWASTA ESA PRAKARSA T.A 2018/2019
}

\author{
Dewi Rulia Br Sitepu \\ STKIP Budidaya Binjai-Sumatera Utara \\ Email : dewiruliasitepu@gmail.com
}

\begin{abstract}
ABSTRAK
Penelitian yang bertujuan untuk mengetahui apakah ada perbedaan hasil belajar siswa yang menggunakan media audiovisual dan tanpa media audiovisual pada materi Struktur dan Fungsi Sel sebagai Unit Terkecil Kehidupan di kelas XI SMA Swasta Esa Prakarsa T.A 2018/2019 dilaksanakan selama bulan Maret - Juli 2018. Penelitian ini merupakan penelitian eksperimen. Populasi dalam penelitian ini adalah seluruh siswa kelas XI IPA SMA Swasta Esa Prakarsa T.A 2018/2019 yang terdiri dari 6 kelas (240 siswa) sedangkan sampel dalam penelitian ini diambil secara random dan terdiri dari dua kelas (80 siswa) yaitu kelas XI IPA-3 (kontrol) dan XI IPA-1 (eksperimen). Alat pengumpul data berupa tes pilihan berganda sebanyak 20 soal setelah tes diuji terlebih dahulu validitas, reliabilitas, daya beda soal dan tingkat kesukaran soal. Hasil penelitan menunjukkan bahwa data nilai siswa baik pre tes maupun post tes dari kedua sampel yang diuji dengan uji normalitas Liliefors berdistribusi normal sedangkan untuk uji homogenitas dengan uji $\mathrm{F}$, data pre tes dan post tes dari kedua sampel tersebut memiliki varians yang sama (homogen). Selain itu, hipotesis yang diuji dengan menggunakan uji t menunjukkan bahwa ada perbedaan yang signifikan antara hasil belajar siswa yang menggunakan media audiovisual dan tanpa media audiovisual $\left(\mathrm{t}_{\text {hitung }} 7,91>\right.$ $t_{\text {tabel }}$ 1,99). Hasil belajar siswa dengan menggunakan media audiovisual lebih tinggi $\bar{X}_{1} \pm \mathrm{SD}_{1}=7,88 \pm 1,03$ daripada hasil belajar siswa tanpa menggunakan media audiovisual $\bar{X}_{2} \pm \mathrm{SD}_{2}=6,06 \pm 1,02$. Jika dipersentasekan maka hasil belajar siswa yang menggunakan media audiovisual lebih besar yaitu 80,32\% sedangkan pada siswa yang tidak menggunakan media audiovisual yaitu 51,37\%. Dengan demikian media audiovisual sangatlah penting dalam proses belajar mengajar demi pencapaian tujuan pembelajaran.
\end{abstract}

Kata kunci : media audiovisual, sel

\section{PENDAHULUAN}

Penggunaan media pembelajaran merupakan unsur yang sangat mendukung peningkatan prestasi belajar siswa di sekolah. Dikatakan demikian karena media merupakan alat bantu dan sumber belajar dalam proses belajar mengajar sehingga dapat melicinkan jalan menuju tercapainya tujuan pembelajaran. Media dapat 
menambah ketertarikan dan minat belajar siswa serta memperjelas materi pelajaran yang diberikan oleh guru. Sebagaimana terdapat dalam Undang - Undang No. 2 tahun 1989 tentang Sistem Pendidikan Nasional, pasal 35, yaitu setiap satuan pendidikan jalur pendidikan sekolah, baik yang diselenggarakan oleh pemerintah maupun masyarakat harus menyediakan sumber belajar. Jadi pendidikan tidak mungkin terselenggara dengan baik bilamana para tenaga kependidikan maupun para peserta didik tidak didukung oleh sumber belajar yang diperlukan untuk penyelenggaraan kegiatan belajar yang bersangkutan. Terlebih dalam pembelajaran biologi sebagai ilmu sains harus membutuhkan media karena selalu dilengkapi dengan gambar-gambar suatu sistem dan sebagainya.

Setiap materi pelajaran tentu memiliki tingkat kesukaran yang bervariasi. Pada satu sisi ada bahan pelajaran yang tidak memerlukan alat bantu, tetapi di lain pihak ada bahan pelajaran yang sangat memerlukan alat bantu media pengajaran seperi gambar, charta, dan sebagainya. Bahan pelajaran dengan tingkat kesukaran yang tinggi tentu sukar diproses oleh siswa. Apalagi bagi siswa yang kurang menyukai bahan pelajaran yang disampaikan itu. Pastilah siswa akan cepat merasa bosan dan lelah. Mereka hanya akan mengkhayal dan berandai- andai saat melihat papan tulis yang dihiasi kapur dan guru yang hanya memberikan ceramah kepada mereka. Hal ini sudah pasti dapat mempengaruhi prestasi belajar siswa. Namun, pada kenyataannya sekarang ini masih banyak guru yang belum menggunakan media audiovisual sebagai alat bantu dan sumber belajar.

Media audiovisual seperti VCD dapat merangsang gairah dan motivasi belajar siswa karena adanya unsur suara dan gambar dengan warna - warni yang menarik perhatian siswa untuk belajar. Siswa akan belajar lebih banyak dari pada jika materi pelajaran disajikan hanya dengan stimulus pandang atau hanya stimulus dengar. Siswa juga akan lebih tertantang untuk mendalami pelajaran dengan menemukan masalah dari materi pelajaran yang disajikan melalui media yang ditampilkan. Selain itu dengan melihat dan mendengar siswa akan lebih mudah menyerap dan mengingat materi pelajaran yang disajikan karena menurut Dale dalam Arsyad (1995) memperkirakan bahwa pemerolehan hasil belajar melalui indera pandang dan indera dengar memiliki perbedaan, yaitu sekitar $75 \%$ hasil belajar seseorang diperoleh melalui indera pandang sekitar $13 \%$ diperoleh melalui indera dengar, dan sekitar $12 \%$ diperoleh melalui indera lainnya. 
Penelitian yang berkaitan dengan penggunaan media audiovisual sebagai media pengajaran biologi yang dapat meningkatkan prestasi belajar siswa dilakukan oleh Ginting (2006). Ia menunjukkan prestasi belajar siswa pada pokok bahasan keanekaragaman hayati yang diajarkan dengan media audiovisual pada siswa kelas X semester 1 di SMA Negeri 2 Kabanjahe Tahun Pelajaran 2005-2006 diperoleh rata-rata dari tes akhir 7,651 sedangkan yang tidak menggunakan media audiovisual adalah 6,118. Jadi, terdapat perbedaan antara hasil belajar siswa yang menggunakan media audiovisual dengan yang tidak menggunakan media audiovisual.

Media audiovisual adalah media yang mempunyai unsur suara dan unsur gambar. Media audiovisual disajikan dengan menggunakan mesin-mesin mekanis dan elektronik untuk menyampaikan pesan-pesan audio dan visual, misalnya film bersuara, video, televisi, dan sound slide. Ciri-ciri utama teknologi media audiovisual adalah : (1) Mereka biasanya bersifat linear, (2) Mereka biasanya menyajikan visual yang dinamis, (3) Mereka digunakan dengan cara yang telah ditetapkan sebelumnya oleh perancang/pembuatannya, (4) Mereka merupakan representasi fisik dan gagasan real atau gagasan abstrak, (5) Mereka dikembangkan menurut prinsip psikologis behaviorisme dan kognitif, (6) Umumnya mereka berorientasi kepada guru dengan tingkat pelibatan interaktif murid yang rendah.

\section{TUJUAN PENELITIAN}

Adapun tujuan penelitian ini adalah untuk mengetahui perbedaan hasil belajar siswa yang menggunakan media audiovisual dan tanpa media audiovisual pada materi Struktur dan Fungsi Sel Sebagai Unit Terkecil Kehidupan di kelas XI SMA Swasta Esa Prakarsa T.A 2018/2019

\section{METODE PENELITIAN}

Penelitian ini dilaksanakan di SMA Swasta Esa Prakarsa T.A 2018/2019 Populasi dalam penelitian ini adalah kelas XI IPA SMA Swasta Esa Prakarsa T.A 2018/2019 yang terdiri dari 6 kelas XI IPA dengan jumlah populasi keseluruhan adalah 240 orang. Sampel dalam penelitian ini diambil secara acak (random) dengan undian. Terdiri dari 2 kelas yaitu kelas XI IPA-1 sebanyak 40 siswa sebagai kelas eksperimen dan kelas XI IPA-3 sebanyak 40 siswa sebagai kelas kontrol. Penelitian ini merupakan penelitian eksperimental yang bertujuan untuk mengetahui apakah ada perbedaan hasil belajar siswa yang menggunakan media audiovisual dan tanpa media audiovisual pada Materi Struktur dan Fungsi Sel Sebagai Unit Terkecil Kehidupan 
di kelas XI SMA Swasta Esa Prakarsa T.A 2018/2019 Penelitian dilakukan dengan tahapan sebagai berikut : Tahap Persiapan meliputi (a) Melakukan observasi; (b) Menetapkan jadwal penelitian; (c) Menyusun rencana pelaksanaan pembeljaran (RPP); (d) Menyiapkan media; (e) Menyiapkan soal tes; (f) Uji tes awal. Tahap pelaksanaan penelitian meliputi Pengambilan sampel dari populasi; (b) Membagi sampel menjadi kelas kontrol dan kelas eksperimen, kemudian kelas kontrol dan kelas eksperimen dilakukan pre test untuk mendapatkn data awal; (c) Siswa diberi pengajaran tentang Materi Struktur dan Fungsi Sel, di kelas eksperimen diterapkan pembelajaran dengan menggunakan media audiovisual sedangkan untuk kelas kontrol diterapkan pembelajaran konvensional tanpa media audiovisual; (d) Siswa diberi post test untuk mengukur hasil belajar siswa; (e) Setelah itu dilakukan analisa data

\section{PEMBAHASAN DAN HASIL PENELITIAN}

Data yang diperoleh dari hasil penelitian (pre tes dan post tes) setelah dilakukan analisis data berupa uji normalitas dengan menggunakan uji Liliefors diketahui bahwa data tersebut berdistribusi normal baik pada kelas eksperimen (dengan media audiovisual) maupun kelas kontrol (tanpa media audiovisual). Sedangkan untuk uji homogenitas dengan menggunakan uji $F$ diketahui bahwa data pre test dan post tes pada kedua kelas memiliki varians yang sama (homogen).

Hasil pengujian hipotesis dengan menggunakan uji t pada taraf signifikasi $5 \%$ menunjukkan ada perbedaan yang signifikan antara hasil belajar siswa yang menggunakan media audiovisual dan tanpa media audiovisual pada materi Struktur dan Fungsi Sel Sebagai Unit Terkecil Kehidupan di kelas XI SMA SMA Swasta Esa Prakarsa T.A 2018/2019 . Berdasarkan data nilai siswa untuk kelas eksperimen diperoleh nilai rata-rata pre tes $\bar{X}_{1} \pm \mathrm{SD}_{1}=4,37 \pm 1,03$ dan nilai rata-rata post tes $\bar{X}_{1} \pm \mathrm{SD}_{1}=7,88 \pm$ 1,03 sedangkan untuk kelas kontrol diperoleh nilai rata-rata pre tes $\bar{X}_{2} \pm \mathrm{SD}_{2}=$ $4,03 \pm 1,04$ dan nilai rata-rata post tes sebesar $\bar{X}_{2} \pm \mathrm{SD}_{2}=6,06 \pm 1,02$. jika hasil belajar siswa dari kedua kelas sampel dipersentasikan maka diperoleh hasil belajar siswa untuk kelas eksperimen adalah $80,32 \%$ sedangkan untuk kelas kontrol adalah 50,37\%. Hal ini menunjukkan bahwa hasil belajar siswa yang diajar dengan menggunakan media audiovisual lebih tinggi dibandingkan dengan hasil belajar siswa yang diajar tanpa menggunakan media audiovisual. Hal ini didukung dengan hasil 
penelitian Ginting (2006) yang menyatakan bahwa terdapat perbedaan yang signifikan antara hasil belajar siswa yang menggunakan media audiovisual dan tanpa media audiovisual dimana nilai rata-rata kelas eksperimen $\quad \bar{X} \pm \mathrm{SD}=7,651 \pm 1,297$ sedangkan untuk kelas kontrol $\bar{X} \pm \mathrm{SD}=$ $6,118 \pm 1,359$.

Lebih tingginya hasil belajar siswa kelas eksperimen disebabkan oleh adanya penggunaan media audiovisual berupa VCD pembelajaran sebagai media pembelajaran. Dengan adanya media audiovisual maka siswa akan belajar dengan menggunakan indra ganda yaitu indera pandang dan dengar. Hal ini akan memberikan keuntungan bagi siswa. Siswa akan belajar lebih banyak daripada jika materi pelajaran disajikan hanya dengan stimulus pandang atau hanya dengan stimulus dengar. Penggunaan media ini dapat melibatkan siswa secara langsung untuk lebih ingin mengetahui materi sel yang diajarkan dan siswa merasa tertarik dengan materi sel yang disajikan melalui tayangan VCD tersebut. Siswa tidak hanya mendengarkan materi sel tetapi juga dapat melihat tampilan gambar sel berikut bagian-bagiannya yang lebih menarik sehingga siswa dapat lebih mudah dan lebih cepat memahami materi sel. Selain itu siswa akan lebih mudah mengingat materi yang telah diajarkan. Sehingga pada saat diberikan tes maka siswa akan lebih mudah menjawab soal-soal dalam tes tersebut. Hal ini dibuktikan dengan banyaknya nilai siswa di atas nilai Kriteria Ketuntasan Minimal (KKM) di sekolah tersebut yaitu 6,5. Dengan demikian, media tersebut dapat menjembatani informasi dari guru ke siswa. Hal inilah yang dapat merangsang gairah dan motivasi siswa untuk aktif belajar di kelas. Sesuai dengan pendapat Sudjana dan Rivai dalam Arsyad (1995) yang menyatakan bahwa :

"Pengajaran dengan media akan lebih menarik perhatian siswa sehingga dapat menumbuhkan motivasi belajar. Selain itu, bahan pengajaran akan lebih jelas maknanya sehingga dapat lebih dipahami oleh siswa dan memungkinkannya menguasai dan mencapai tujuan pengajaran".

Berbeda dengan siswa yang diajar tanpa media audiovisual (kelas kontrol), hasil belajar mereka lebih rendah. Hal ini terjadi karena siswa tersebut hanya diberi materi sel melalui penjelasan dari guru saja sehingga siswa akan cepat merasa bosan dan berdampak pada kurangnya gairah dan motivasi mereka dalam mengikuti pelajaran. Siswa menjadi lebih sulit memahami materi sel yang diberikan guru sehingga hasil belajar mereka menjadi lebih rendah ketika diberikan tes. Hal itu terlihat dari dari sedikitnya nilai siwa yang mencapai nilai KKM. 
Pada prinsipnya penggunaan media audiovisual yang baik dapat membantu proses belajar mengajar dengan menarik perhatian siswa untuk lebih mengikuti pelajaran. Namun, ada beberapa hal yang perlu diperhatikan dalam penggunaan media audiovisual ini agar pembelajaran lebih efektif dan efisien, diantaranya adalah : (1) guru senantiasa memperhatikan situasi belajar agar siswa dapat mengikuti pembelajaran dengan baik; (2) guru senantiasa memperhatikan alokasi penayangan video pembelajaran agar guru juga dapat menjelaskan materi yang diajarkan. Jadi, peran media sebagai alat bantu dalam proses belajar mengajar menjadi lebih baik.

Berdasarkan hasil penelitian maka diketahui ada perbedaan yang sigifikan antara hasil belajar siswa yang menggunakan media audiovisual dan tanpa media audiovisual pada materi Struktur dan Fungsi Sel Sebagai Unit Terkecil Kehidupan di kelas XI SMA Swasta Esa Prakarsa T.A 2018/2019 Oleh karena itu, penggunaan media audiovisual dalam proses belajar mengajar sangatlah dibutuhkan demi pencapaian tujuan pembelajaran.

\section{KESIMPULAN}

Berdasarkan uraian hasil penelitian di atas maka dapat diperoleh kesimpulan sebagai berikut terdapat perbedaan yang signifikan antara antara hasil belajar siswa yang menggunakan media audiovisual dan tanpa media audiovisual pada materi Struktur dan Fungsi Sel Sebagai Unit Terkecil Kehidupan di kelas XI SMA Swasta Esa Prakarsa T.A 2018/2019 yang dapat digambarkan dari hasil nilai rata-rata dan standard deviasi dari data post tes kelas eksperimen (menggunakan media audiovisual) sebesar $\bar{X}_{1} \pm \mathrm{SD}_{1}=7,88 \pm 1,03$ dan kelas kontrol (tanpa menggunakan media audiovisual) sebesar $\bar{X}_{2} \pm \mathrm{SD}_{2}=$ $6,06 \pm 1,02$.

\section{SARAN}

Beberapa saran yang perlu disampaikan pada penelitian ini adalah sebagai berikut

1. Hendaknya para guru Biologi dapat menggunakan media audiovisual sebagai alternatif dalam proses belajar mengajar karena penggunaan media ini dapat meningkatkan hasil belajar siswa.

2. Bagi para guru Biologi yang ingin menerapkan pengajaran dengan menggunakan media audiovisual sebaiknya memperhatikan kondisi siswa di dalam kelas, alokasi waktu yang telah 
direncanakan serta sarana dan prasarana tujuan pembelajaran yang ingin dicapai. belajar dengan baik agar diperoleh

3. Hendaknya perlu dilakukan penelitian lanjutan tentang penggunaan media audiovisual dalam pembelajaran Biologi dengan materi Biologi yang berbeda. 


\section{DAFTAR PUSTAKA}

Arikunto, S., (2005), Manajemen Penelitian, Rineka Cipta, Jakarta.

Arsyad, A., (1997), Media Pengajaran, Raja Grafindo Persada, Jakarta.

Dahar, R.W., (1996), Teori-Teori Belajar, Erlangga, Jakarta.

Daryanto, H., (2000), Evaluasi Pendidikan, Rineka Cipta, Jakarta.

Djamarah, S.B. dan Aswan Zain, (2006), Strategi Belajar Mengajar, Rineka Cipta, Jakarta.

Ginting, S.C., (2006), Efektivitas Peggunaan Media Audiovisual terhadap Keberhasilan Belajar Siswa SMU Negeri 2 Kabanjahe., Skripsi, FMIPA, Unimed, Medan.

Harahap, T.S., (2008), Perbedaan Hasil Belajar Siswa yang Memperoleh Pembelajaran Kooperatif Tipe TPS dengan Konvensional pada Pokok Sistem Persamaan Linear 2 Variabel di Kelas VIII SMP Swasta YPI Deli
Tua Tahun Pelajaran 2007/2008, Skripsi, FMIPA, Unimed, Medan.

Pratiwi, D.A., dkk, (2006), Biologi Untuk SMA Kelas XI, Erlangga, Jakarta.

Poerwadarminta, W.J.S., (1995), Kamus Umum Bahasa Indonesia, Balai Pustaka, Jakarta.

Riandari, H., (2007), Sains Biologi 2, Tiga Serangkai Pustaka Mandiri, Solo.

Sudjana, N., (2005), Metode Statistika, Tarsito, Bandung.

Sudjana, N., (2008), Penilaian Hasil Proses Belajar Mengajar, Remaja Rosdakarya, Bandung.

Suryabrata, S., (2005), Psikologi Pendidikan, Raja Grafindo Persada, Jakarta.

Syah, M., (2004), Psikologi Pendidikan dengan Pendekatan Baru, Remaja Rosdakarya, Bandung. 